\title{
E-mobile Acceptance Using Unified Theory of Acceptance and Use of Technology (UTAUT): Research on Universities in Jordan
}

\author{
Saleem Issa Al-Zoubi ${ }^{1}$ and Maaruf Ali ${ }^{2, *}$ \\ ${ }^{1}$ Department of Computer Science, Irbid National University, Irbid, Jordan \\ saleem.alzoubi@inu.edu.jo \\ 2Dept. of Comp. Eng., Epoka University, Rruga Tiranë-Rinas, Km 12, 1032, Vorë, Tiranë, Albania \\ mali@epoka.edu.al \\ *Correspondence: maaruf@ieee.org
}

Received: $1^{\text {st }}$ September 2019; Accepted: $18^{\text {th }}$ September 2019; Published: $1^{\text {st }}$ October 2019

\begin{abstract}
An investigation into the variables that have a bearing on the acceptance of D-learning (Digitallearning) services such as E-learning and M-learning, in Jordanian universities is presented. This is followed with a discussion on modernising M-learning with emerging technologies. The study fuses the Unified Theory of Acceptance and Use of Technology ("UTAUT") model with the cultural paradigm and educational variables. 100 valid questionnaires distributed to random Jordanian students in two cities were used to collect the primary data. The IBM SPSS ${ }^{\circledR}$ (Statistical Package for the Social Sciences) software platform was used to analyse the data. The validity of the overall model was proven statistically with an acceptable fit of the data to the measurement model. The findings show that the factor with the highest direct effect on "Intention to use Mlearning" is the "Attitude toward using M-learning". Whilst the factor with the highest indirect effect on "Intention to use M-learning" is "Compatibility". The conclusions are that the: cultural factor has a significant and positive impact on the "perceived usefulness" and "perceived ease of use". "Perceived usefulness" and "perceived ease of use" have the greater impact on the "customers" attitude", which consequently influences the students" "intention to use M-learning services". The findings also indicate that educational variables such as the attainment value, self-management of learning and the perceived enjoyment significantly affected $M$ learning adoption intention. Emerging technologies such as the Cloud, AI (Artificial Intelligence) and the Blockchain and how they may be utilised to enhance the delivery of M-learning is discussed throughout the paper.
\end{abstract}

Keywords: Unified Theory of Acceptance and Use of Technology Model; UTAUT; D-learning; Mobile Learning Services; Mobile Learning; M-learning; Culture; E-learning

\section{Introduction}

Mobile-learning (M-learning) is a type of learning that can potentially happen anytime or anywhere, with the use of a portable electronic computing device [1]. This can either be offline or online. 
Furthermore, this method of remote learning creates a more personalised learning experience [2]. Additionally, utilising portable, networked mobile communication and cellular devices, the users access learning applications in a selection of diverse contexts when interacting within their local environment or with other non-geographic users. Moreover, M-learning is increasingly growing and moving from asynchronous to synchronous instructor-to-learner communication and content delivery. This has been brought about owing to the rapid advances in computer networking and multimedia technology. Specifically, asynchronous learning encompasses gaining information without the presence of the instructor and thus no instructor-learner interaction takes place. Such an example being reading and understanding an online article on a mobile device solely by the user without any assistance by anybody else, even be it a friend. On the other hand, synchronous learning comprises of active back and forth instructor-learner interaction, such as the learner participating in an online webinar by posting questions or making comments using a video conferencing or electronic real-time mark-up board tool or using a smartphone. M-learning is not restricted by time-and-space limitation, as it has now become a method that allows both educators and students to communicate utilising a variety of learning tools through mobile communicating devices or gadgets [3]. Even synchronous Mlearning can be asynchronous in the sense that the human lecturer may be replaced by a synthetic AI entity performing the rôle of the peripatetic. The student may access this virtual person anytime. The Cloud will also offer more flexibility in delivery and accessibility to the learning material. The use of mobile devices being many, principally now comprises of audio (voice) and video calls, internet and social networking site access, sending and receiving emails, capturing and sharing pictures/videos and playing (interactive and often real-time) games along with listening to music and watching films. Thus, the handheld devices function with one of these three common modes and qualities, viz.: utility, communication or for fun/leisure [4,5] activities.

\section{Literature Review}

According to [6], M-learning is a significant alternative platform for learning services in which having the knowledge on the influencing elements for M-learning acceptance amongst higher education learners is crucial. Apart from that, as stated in [7], an individual's volition and conscious participation in M-learning activities are some of the success keys for M-learning.

Further, when factors associated with acceptance of mobile learning are identified, the universities implementing this learning method can improve on the delivery of services to the students. Apart from that, when these factors are incorporated into the business process, education and learning will become more efficient and there will consequently be an increase in the loyalty of the students [5-8]. However, according to [9], the university would have to take into careful consideration the potential factors that may influence the students' intention and understand how these factors could entice them to use it in order to invest in the development of university delivered mobile services and creative content properly. Nonetheless, it would be difficult for the students to acquire the pedagogical information if they fail to accept and encompass the new technology designed to deliver it in the first place. Reassurances must be offered to the user, such as offering privacy of information and security of information flow. This may be enabled by using blockchain technology. Payment processing in cryptocurrency will also expand M-learning to an even greater audience and consumers beyond just university students, with a potential transnational market base.

Apart from that, considering that the market for mobile learning has gradually become global, cultural difference also becomes an important factor. Thus, universities or training organisations should have the knowledge of cultural difference so that they can earn a significant competitive edge [8], [10, 11]. According to [10], the cultural perspectives of mobile learning in the Malaysian context is an aspect that has yet to be covered. However, it must be pointed out here that M-learning needs to be cognizant of both mobile users and nomadic users. Nomadic users make use of the computing nodes, devices and platforms around them, whilst mobile users carry their own devices. M-learning needs to be deployable, accessible and functional across all types of devices, ensuring critical operational functionality when a user is offline too. Content may be downloaded for future offline use. There is 
thus a need for a universal accessibility learning approach in the mobile and nomadic computing age. Inasmuch as to embrace the often, primary rôle of the user's mobility and communication to Mlearning. So, the effectiveness of existing models still needs to be enhanced, to which researchers have pointed out parameters that must be considered, with culture being one. With the widespread proliferation of Internet of Things (IoT) objects, it must be appreciated that M-learning devices are themselves also IoTs, which may be networked to other IoTs. This study is paramount in consolidating the chasm in the development of services in order to create more efficiency and relevance in the education environment - all of which could be achieved through the expansion and use of the UTUAT model.

\section{Theoretical Background}

\subsection{Unified Theory of Acceptance and Use of Technology (UTAUT)}

[12] had formerly conducted a study to draw a comparison between the similarities and differences amongst the established models and theories of user acceptance and from their studies they formulated the UTAUT paradigm. The steps to deriving this model involved comparisons utilising the: technology acceptance model (TAM) [13], theory of planned behaviour (TPB) [14], theory of reasoned action (TRA) [15] and several others. The resultant UTAUT model was made to counter the problems being faced by researchers in the sphere of IT during the construction of their study framework as an attempt to create understanding towards the usage of technology amongst the users [12].

Further, [13] added that the acceptance models established in the past had some successful records in an approximate estimate of 40 percent in their prediction of the adoption of information technology. By contrast, [12] reported that the use of their UTAUT model helped prediction of the uptake of IT in the region of 70 percent, in their study of the variance in the users' intention. The UTAUT model is also suitable to predict equally the individual acceptance of IT for a large range of groups. Scales that have been adopted in prior technology acceptance models and theories were brought together to develop new scales and tested for further enhanced improvement [12].

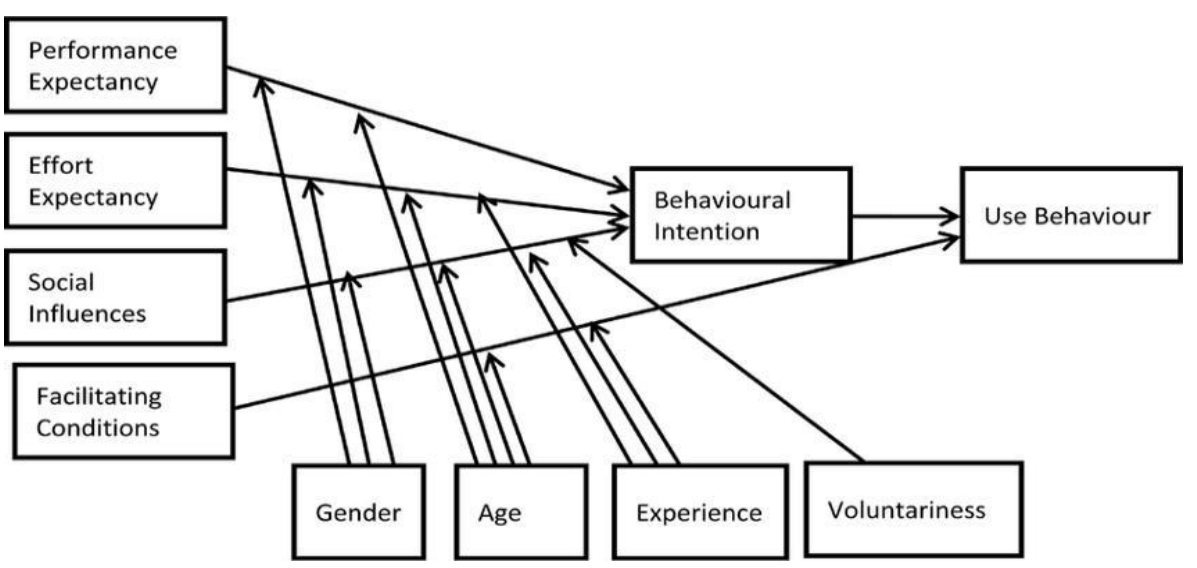

Figure 1. The Original UTAUT Model [12].

For predicting the users' behavioural intention and the behaviour of use, four constructs are used by UTAUT. These constructs are [12]:

a) social influence, this could be by for example from mass media advertising and the influence of family and friends;

b) effort expectancy, how hard is it to accomplish the task;

c) performance expectancy, how will it enhance the ability to carry out the task in the future and

d) facilitating conditions, what environment is in place that is conducive to undertake the training for example.

With respect to the linkage between these constructs, behaviour intention and behaviour of use is moderated by four primary factors including the [12]: 

a) age of the person;
b) gender of the person;
c) voluntariness (willingness) and
d) experience [12], prior or recently acquired.

Fig. 1 illustrates the UTAUT model, whilst Fig. 2 illustrates the proposed modified model.

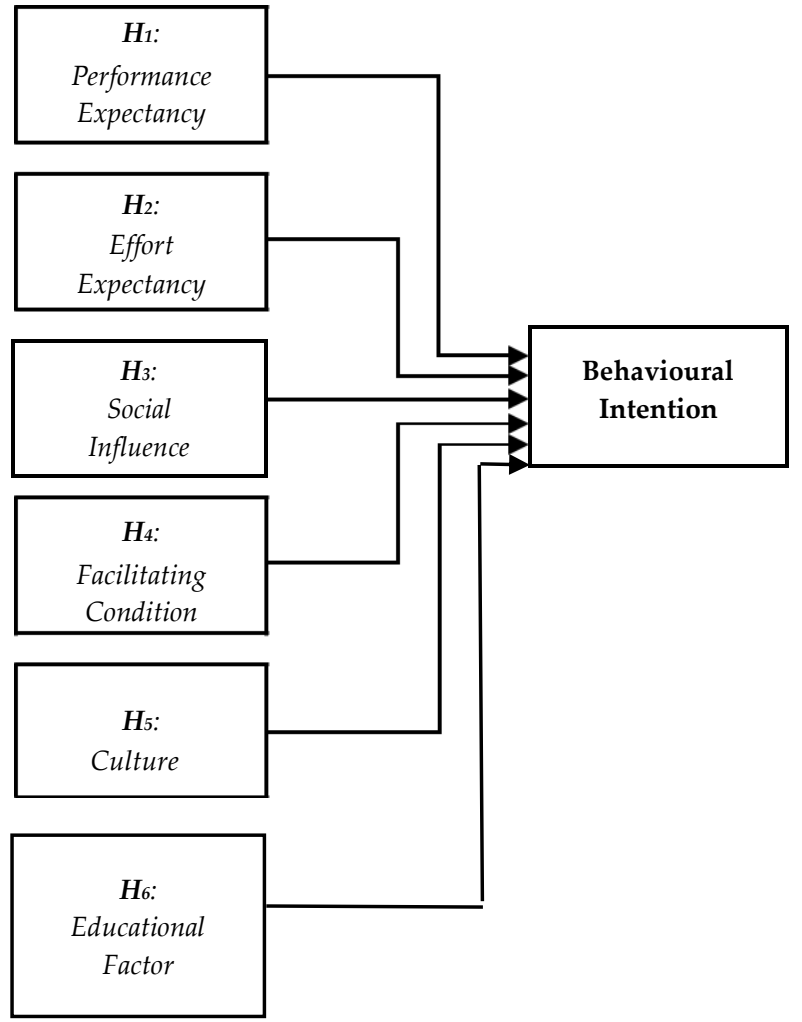

Figure 2. Proposed Research Model.

\subsection{Research Model Factors}

\subsubsection{Culture Factor $(\mathrm{CF})$}

Culture refers to, "the collective programming of the mind which distinguishes the members of one group or category of people from another" [16] or basically expressed, "culture is" [any] "shared values of a particular group of people" [17]. Further, according to [18], culture indicates the individual's "core values and beliefs which" [were] "formed" [during] "childhood and reinforced throughout life", while [19] define culture being, "the beliefs, philosophy, shared values, attitudes, customs, norms, rituals, common practices, and traditions which govern the ways of living of a group of people." Culture can also be expressed in terms of values and norms, where values, according to [20], are what is worth doing or having, and are shaped by experience with parents, school, religion, and the media, while norms as highlighted by [21,22,23], encompass any shared beliefs with regard to behaviour. On the other hand, [24] observes culture as discrepancies that occur between the beliefs, values, and motivations of groups that are dissimilar from one another, while other scholars such as Samovar [25] perceive culture as the sum of values, beliefs, attitude, experience, knowledge, religion, meanings, hierarchies, spatial relationships, rôles, universal concepts, notions of time and material objects and possessions attained by a group along the timeline of generations by the group and individuals.

\subsubsection{Educational Factors (EF)}

To be a successful learner, a person needs "self-management" of the learning process. Selfmanagement here refers to the degree to which the person considers that he or she is self-disciplined. Moreover, it also moderates the extent to which the person can fully engage in autonomous learning 
[27]. The other consequent measure is "successful learning". This results from the learner's overall control of the learning activity, academic exploration and experimentation, asking pertinent and relevant questions and engaging in collaborative discourse [28]. In the scope of M-learning, students must therefore manage their own learning. There is often no choice in this matter as they will often be separated from their faculty, peers and not have readily available institutional support due to various reasons. Acquiring this autonomous trait necessitates skills in critical thinking, identification of focussed learning needs and locating and evaluating the resources [29], [30] required for its accomplishment. As a result, self-management of learning is included in this research. The "perceived enjoyment" refers to the person's performance or engagement in an activity due to his or her interest in the activity. [30], [31], [32] have shown that "perceived enjoyment" is a significant determinant of the behavioural intention to use M-Learning and mobile services. This means that learning activities must be made more enjoyable to the participants in order to promote the learner's acceptance and use of M-Learning. Therefore, perceived enjoyment is included in the study.

\subsection{Research Hypothesis}

The following are the research alternative hypotheses factors for this case study, shown in Fig. 2:

$H_{1}$ : The performance expectancy has a correlation with intention to use mobile learning.

$\boldsymbol{H}_{2}$ : The effort expectancy has a correlation with intention to use mobile learning.

$\mathrm{H}_{3}$ : Social influence has a correlation with intention to use mobile learning.

$\boldsymbol{H}_{4}$ : Facilitating conditions has a correlation with intention to use mobile learning.

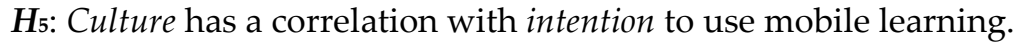

$\mathbf{H}_{6}$ : Educational factor has a correlation with intention to use mobile learning.

\section{Research Methodology}

This research employed 100 Jordanian university students (of both genders) aged 20 years and above as the respondents. The data was extracted from participants filling in online questionnaires (www.surveyshare.com). The questionnaire contained one part which represented several constructs. The Likert scale (with five points) was used to score the user's acceptance level. This was then statistically post-processed to measure the correlation between the six primary elements and the intention to utilize mobile learning. Regression analysis was used in this research. The results of the statistical analysis were used to create a framework that encompassed the capacity of measuring the citizens eagerness to mobile learning. Thus, validation to the Culture parameter with the Unified Theory of Acceptance and Use Technology (UTAUT) was ascertained.

\subsection{Questionnaire Development}

The writing of the questions was for ascertaining the respondents' knowledge of access to the online material. Feedback based on the respondent's comments were used to make minor changes to the questionnaire. Whilst the validity and readability of the content were confirmed. Using the IBM SPSS ${ }^{\circledR}$ (Statistical Package for the Social Sciences) software platform, a pilot study was conducted. This allowed for the testing of the reliability and validity of the model. For the pilot test, the Cronbach's alpha reliability measure was used to test for internal consistency. Factor analysis was also conducted on the data, with the samples collected using convenient sampling. Table 1, below, shows that all the items have values larger than 0.70 (proposed cut-off). 
Table 1. Pilot Questionnaire $(n=31)$ for Test of Scale Reliability, Alpha Ranked in Order.

\begin{tabular}{|c|c|c|c|}
\hline Order & Variable & No. of Items & Alpha (a) \\
\hline $\mathbf{1}^{\text {st }}$ & Culture & 4 & 0.897 \\
\hline $\mathbf{2}^{\text {nd }}$ & Behavioural Intention & 4 & 0.874 \\
\hline $\mathbf{3}^{\text {rd }}$ & Effort Expectancy & 4 & 0.811 \\
\hline $\mathbf{q}^{\text {th }}$ & Performance Expectancy & 4 & 0.784 \\
\hline $\mathbf{4}^{\text {th }}$ & Social Influence & 4 & 0.784 \\
\hline $\mathbf{6}^{\text {th }}$ & Facilitating Conditions & 4 & 0.747 \\
\hline $\mathbf{7}^{\text {th }}$ & Educational Factor & 9 & 0.911 \\
\hline
\end{tabular}

\section{Data Analysis and Results}

The assessment of the structural model with respect to the measurement model was undertaken using SPSS analysis including towards the inner model. The proposed requirements in [26] were investigated. The hypotheses were tested by the method of bootstrapping for determining the path coefficients' significance levels.

The interactions between the parameters of the research model was determined using multiple regression analysis. The test indicated some influences between the factors. Three regression models, containing the five hypotheses, were used for the analysis, as shown in Table 2.

Table 2. Pilot Questionnaire $(n=31)$ for Test of Scale Reliability, Alpha Ranked in Order.

\begin{tabular}{|c|c|c|c|c|}
\hline Hypotheses & & Variable & $\beta$ & Supported \\
\hline$H_{1}$ & Performance Expectancy & »»»» Behavioural intention to use (BI) & $0.387^{* *}$ & Yes \\
\hline $\mathrm{H}_{2}$ & Effort Expectancy & »m» Behavioural intention to use (BI) & $0.411^{*}$ & Yes \\
\hline $\mathrm{H}_{3}$ & Social Influence & mm» Behavioural intention to use (BI) & $0.217^{* *}$ & Yes \\
\hline $\mathrm{H}_{4}$ & Facilitating Conditions & "»»» Behavioural intention to use (BI) & $0.342^{* *}$ & Yes \\
\hline$H_{5}$ & Culture & "»» Behavioural intention to use (BI) & $0.477^{* *}$ & Yes \\
\hline$H_{6}$ & Educational factor & mm» Behavioural intention to use (BI) & $0.486^{* *}$ & Yes \\
\hline
\end{tabular}

The asterisks in the regression table corresponds as: one asterisk means " $p<0.1$ "; two asterisks mean " $p<0.05$ ".

\section{Discussion}

The readiness to utilise mobile learning services amongst Jordanian students was positively identified. The parameters or factors identified and tested included: culture, effort expectancy, performance expectancy, facilitating conditions, social influence, intention and education. As mobile learning service usage amongst students should be maximized, the educational providers must consider them carefully regarding their optimization. The collection of the data must, however, cover a broader spectrum of the population in order to be more nationally representative. The model for Jordanian university M-learning students took in constructs from the Unified Theory of Acceptance and Use Technology (UTAUT). With respect to culture, optimizing effort expectancy, performance expectancy, social influence, intention and facilitating conditions will all contribute to an increase in the uptake of M-learning in the university domain. The intent to utilize internet delivered services was positive if the participants were convinced that the use of the internet would result in an increase in their efficiency of learning.

For the widespread uptake of D-learning (Digital-learning) which are: M-learning and e-learning - it is essential that it embraces and utilizes emerging technologies. These pioneering technologies include, viz.: cloud delivery; artificial intelligence; the block-chain for added security, and integration with diverse IoT devices. Mobile as well as nomadic users must be catered for, taking into consideration transnational cultural aspects that need to modify the user interface. Thus, the plasticity of the user interface must also be carefully approached.

The results in this study indicate that the "attainment value" is a significant determinant of students' intention to use mobile devices for learning. For university staff and educators in general, the positive attitudes of students must hence be engendered with their personal values, multi-life 
commitments and preparedness for start using M-learning. The second significant factor found in this study was "perceived enjoyment". The results suggested that the more the students enjoyed Mlearning, the more they were motivated to engage in M-learning activities. Given that M-learning is currently voluntary at most institutions and that the target user groups originate from diverse backgrounds, it is important to make the systems interactive and enjoyable for students to use. To further promote the uptake of M-learning, educators and system user interface (UI) designers should consider designing immersive experimental activities that relate the resources to the students' personal experience, varying knowledge level, interests and requirements. In adopting this approach, the students will thus feel more engrossed in the task and more in command of the learning path. This will all help attain the fulfilment of the experience of perceived playfulness and consequently increase system users. This research affirmed that self-management of learning is a major factor in the students' intention to use M-learning. This finding can help educational policy makers, teachers and course designers to author and deploy curricula that engage and sustain the students' capability of learning and continuous self-management of that learning. In addition, educators should assiduously deliver the educational material, to both develop and sustain the students' habit of continuous self-learning and lifelong learning.

\section{Conclusions}

The last decade has seen exponential growth in d-learning (e- and m- learning) in the developed nations. This has not gone unnoticed in the rest of the world, especially in the rapidly developing and lucrative emerging nations of the Middle East. This is because of the governmental plans of many of these oil rich nations to increase the digital literacy of their national subjects. These countries must employ the technology of the Internet coupled with emerging technologies such as the Cloud, Artificial Intelligence, Deep Learning and the Blockchain - to make it appeal to a wider consumer base beyond just the academe. Unfortunately, internet penetration amongst the population is still lagging for nearly all the Middle Eastern countries, compared to the rest of the world. In fact, comparatively few mobile learning websites exist in the Arabic speaking world compared to the Western World.

The outcomes generated by this study has positively identified that to increase the intention to use d-learning in two Jordanian universities, the students must:

i. be immersed in a conducive culture to internet usage for education delivery;

ii. have the intention to follow through the online program;

iii. see that their effort expended must not be seen to be too onerous compared to using traditional non-Internet based learning;

iv. meet their performance expectations after using the d-learning technology;

v. be in an environment that has a positive social influence to using this technology;

vi. find the technology easy to use and it must help facilitate their learning process.

As such, the increase in the number of Arabic university websites delivering d-learning is expected to grow exponentially, especially once coupled with emerging technologies such as the Cloud with its various XAAS (x-As-A-Service) offerings.

\section{References}

1. Behera, S.K., E-and M-Learning: A Comparative Study. Int. J. on New Trends in Education and Their Implications 4(3), 8, p.65 (2013). http://www.ijonte.org/FileUpload/ks63207/File/08.behera.pdf, last accessed 2019/4/17.

2. Kim, D., Rueckert, D., Kim, D. J., Seo, D., Students' Perceptions and Experiences of Mobile Learning. Language,

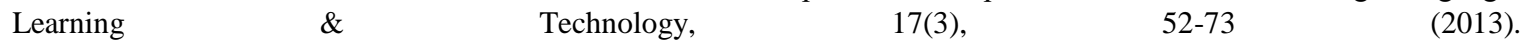
https://scholarspace.manoa.hawaii.edu/bitstream/10125/44339/1/17_03_kimetal.pdf, last accessed 2019/4/17.

3. Goundar, S., What is the Potential Impact of Using Mobile Devices in Education? GlobDev 2011. 16 (2011). https://aisel.aisnet.org/globdev2011/16, last accessed 2019/4/17.

4. Mockus, L., Dawson, H., Edel-Malizia, S., Shaffer, D., An, J.S., Swaggerty, A., The impact of mobile access on motivation: Distance education student perceptions. In: $17^{\text {th }}$ Annual Sloan-C Consortium Int. Conf. on Online Learning, Lake Buena Vista, FL. (2011). https://dis-sem.in/p/25066345/the-impact-of-mobile-access-on-motivation-distanceeducation-student-perceptions, last accessed 2019/4/17. 
5. Alzubi, M.M., Alkhawlani, M.A., El-Ebiary, Y.A.B., Investigating the factors affecting University students' e-commerce intention towards: a case study of Jordanian universities. J. of Business and Retail Management Research, 12(1), 189-194 (2017). http://www.jbrmr.com/cdn/article file/content 80576 17-10-04-22-20-41.pdf, last accessed 2019/4/17.

6. Alzaza, N.S., Yaakub, A.R.: Students' Awareness and Requirements of Mobile Learning Services in the Higher Education Environment. American Journal of Economics and Business Administration, 3(1), 95-100 (2011). https://core.ac.uk/download/pdf/25831726.pdf, last accessed 2019/4/17.

7. Liu, Y., Han, S., Li, H., Understanding the Factors Driving M-learning Adoption: A Literature Review. Campus-Wide Information Systems, 27(4), 210-226 (2010). Doi: 10.1108/10650741011073761

8. Pimpaka, P: Mobile Learning, Designing a Socio-Technical Model to Empower Learning in Higher Education. LUX: A Journal of Transdisciplinary Writing and Research from Claremont Graduate University, 2(1), 23 (2013). Doi: 10.5642/lux.201301.23

9. Al-matari, A.Y., Iahad, N.A., Balaid, A.S., Factors Influencing Students' Intention to Use M-learning. J. of Information $\begin{array}{llllll}\text { Systems Research and Innovation, } & \text { 5, } & 1-8 \quad \text { https://sem- }\end{array}$ inar.utmspace.edu.my/jisri/download/Vol5/Pub1_Factors_to_Use_Mobile_learning.pdf, last accessed 2019/4/17.

10. Ariffin, S.A., Mobile Learning in the Institution of Higher Learning for Malaysia students: Culture Perspectives. Int. J. on Advanced Science, Engineering and Information Technology, 1(3), 283-288 (2011). Doi: 10.18517/ijaseit.1.3.59

11. Alzubi, M.M., Al-Dubai, M.M., Farea, M.M., Using the technology acceptance model in understanding citizens' behavioural intention to use m-marketing among Jordanian citizen. J. of Business and Retail Management Research, 12(2), 224-231 (2018). http://www.jbrmr.com/cdn/article file/content 35965 18-01-19-10-55-36.pdf, last accessed 2019/4/17.

12. Venkatesh, V., Morris, M.G., Davis, G.B., Davis, F.D., User Acceptance of Information Technology: Toward a Unified View. Management Information Systems Quarterly, 27(3), 425-478 (2003). https://aisel.aisnet.org/misq/vol27/iss3/5/, last accessed 2019/4/17.

13. Davis, F.D., Perceived Ease of Use, and User Acceptance of Information Technology. MIS Quarterly, 13(3), 319-340 (1989). Doi: $10.2307 / 249008$

14. Ajzen, I., The Theory of Planned Behavior. Organizational Behavior and Human Decision Processes, 50(2), 179-211 (1991). Doi: 10.1016/0749-5978(91)90020-T

15. Ajzen, I., From Intentions to Actions: A Theory of Planned Behavior. In: Kuhl J., Beckmann J. (eds.) Action Control. SSSP Springer Series in Social Psychology. Springer, Berlin, Heidelberg (1985). doi: 10.1007/978-3-642-69746-3_2

16. Hofstede, G., Cultures and Organizations: Software of the mind. McGraw-Hill, NY, USA (1991).

17. Erez, M., Earley, P.C.: Culture, self-identity, and work. Oxford University Press, NY, USA (1993).

18. Shore, B., Venkatachalam, A.R., Role of national culture in the transfer of information technology. The J. of Strategic Information Systems, 5(1), 19-35 (1996). Doi: 10.1016/S0963-8687(96)80021-7

19. Hasan, H., Ditsa, G., The impact of culture on the adoption of IT: an interpretive study. J. of Global Information Management, 7(1), 5-15 (1999). Doi: 10.4018/jgim.1999010101

20. Van Maanen, J., Laurent, A., The Flow of Culture: Some Notes on Globalization and the Multinational Corporation. In: Ghoshal S., Westney D.E. (eds.) Organization Theory and the Multinational Corporation. Palgrave Macmillan, London (1993). Doi: 10.1007/978-1-349-22557-6_12

21. Hill, C.E., Loch, K.D., Straub, D., El-Sheshai, K., A Qualitative Assessment of Arab Culture and Information Technology Transfer. J. of Global Information Management, 6(3), 29-38 (1998). Doi:10.4018/jgim.1998070103

22. Straub, D.W., The Effect of Culture on IT Diffusion: E-Mail and FAX in Japan and the U.S. Information Systems Research, 5(1), 23-47 (1994). Doi: 10.1287/isre.5.1.23

23. Straub, D., Keil, M., Brenner, W., Testing the technology acceptance model across cultures: A three country study. Information \& Management, 33(1), 1-11 (1997). Doi: 10.1016/S0378-7206(97)00026-8 
24. Goodman, S.E., Green, J.D., Computing in the Middle East. Communications of the ACM, 35(8), 21-24 (1992). Doi: $10.1145 / 135226.135236$

25. Samovar, L.A., Porter, R.E., McDaniel, E.R., Communication Between Cultures. Wadsworth Publishing Company Inc. (2009).

26. Hair, J.F., Black, W.C., Babin, B.J., Anderson, R.E.: Multivariate Data Analysis. (7 $7^{\text {th }}$ ed.). China Machine Press, Beijing, China (2011).

27. Smith, P.J., Murphy, K.L., Mahoney, S.E., Towards identifying factors underlying readiness for online learning: An exploratory study. Distance Education, 24(1), 57-67 (2003). Doi: 10.1080/01587910303043

28. Sharples, M., Disruptive devices: Mobile technology for conversational learning. Int. J. of Continuing Engineering Education and Lifelong Learning, 12(5-6), 2003, pp. 504-520. Doi: 10.1504/IJCEELL.2002.002148

29. Li, W., Virtual knowledge sharing in a cross-cultural context. J. of Knowledge Management, 14(1), 38-50 (2010). Doi: $10.1108 / 13673271011015552$

30. Wang, Y.-S., Wu, M.-C., Wang, H.-Y., Investigating the determinants and age and gender differences in the acceptance of mobile learning. British J. of Educational Technology, 40(1), 92-118, Jan., (2009). Doi: 10.1111/j.14678535.2007.00809.x

31. Moon, J.-W. and Kim, Y.-G., Extending the TAM for a World-Wide-Web context. Information \& Management, 38(4), 217-230, Feb., (2001). Doi: 10.1016/S0378-7206(00)00061-6

32. Huang, J.-H., Lin, Y.-R., Chuang, S.-T., Elucidating user behavior of mobile learning. The Electronic Library, 25(5), 585-598 (2007). Doi: 10.1108/02640470710829569

33. C. Larman, Applying UML and Patterns: An Introduction to Object-Oriented Analysis and Design and Iterative Development, 3rd edition, Pearson Education, Inc., Upper River, New Jersey, 2005.

(C) 2019 by the author(s). Published by Annals of Emerging Technologies in Computing (AETiC), under the terms and conditions of the Creative Commons Attribution (CC BY) license which can be accessed at http://creativecommons.org/licenses/by/4.0/. 